\begin{tabular}{|c|l|}
\hline Title & $\begin{array}{l}\text { Fluorescence polarization-based assay using N-glycan-conjugated quantum dots for screening in hemagglutinin } \\
\text { blockers for influenza A viruses }\end{array}$ \\
\hline Author(s) & $\begin{array}{l}\text { Okamatsu, Masatoshi; Feng, Fei; Ohy anagi, Tatsuy a; Nagahori, Noriko; Someya, Kazuhiko; Sakoda, Y oshihiro; Miura, } \\
\text { Nobuaki; Nishimura, Shin-Ichiro; Kida, Hiroshi }\end{array}$ \\
\hline Citation & $\begin{array}{l}\text { Journal of Virological Methods, 187(2), 390-394 } \\
\text { https://doi.org/10.1016/.jviromet.2012.11.004 }\end{array}$ \\
\hline Issue Date & 2013-02 \\
\hline Doc URL & http:/hdl.handle.net/2115/52274 \\
\hline Type & article (author version) \\
\hline File Information & JVM187-2_390-394.pdf \\
\hline
\end{tabular}

Instructions for use 


\section{Fluorescence polarization-based assay using $N$-glycan-conjugated quantum dots for screening in hemagglutinin blockers for influenza A viruses}

Masatoshi Okamatsu $^{\mathrm{a},}{ }^{*}$, Fei Feng $^{\mathrm{b}}$, Tatsuya Ohyanagi ${ }^{\mathrm{b}}$, Noriko Nagahori ${ }^{\mathrm{b}}$, Kazuhiko Someya ${ }^{\mathrm{c}}$, Yoshihiro Sakoda ${ }^{\mathrm{a}}$, Nobuaki Miura ${ }^{\mathrm{b}}$, Shin-Ichiro Nishimura ${ }^{\mathrm{b}, *}$, Hiroshi Kida $^{\mathrm{a}, \mathrm{d}}$

${ }^{a}$ Laboratory of Microbiology, Department of Disease Control, Graduate School of Veterinary Medicine, Hokkaido University, Sapporo 060-0818, Japan

${ }^{\mathrm{b}}$ Division of Drug Discovery Research, Graduate School of Life Science, and Frontier Research Center for Post-Genome Science and Technology, Hokkaido University, Sapporo 001-0021, Japan.

${ }^{c}$ Vaccine Business Intelligence Division, Vaccine Business Strategy Department, Kasai Research and Development Center, Daiichi Sankyo Co., Ltd, Tokyo 134-8630, Japan.

${ }^{\mathrm{d}}$ Research Center for Zoonosis Control, Hokkaido University, Sapporo 001-0020, Japan.

* To whom correspondence should be addressed.

MO: Tel: +81-11-706-5209; Fax: +81-11-706-5208; E-mail: okamatsu@vetmed.hokudai.ac.jp

SN: Tel: +81-11-706-9043; Fax: +81-11-706-9042; E-mail: shin@glyco.sci.hokudai.ac.jp 


\begin{abstract}
Attachment of influenza virus to susceptible cells is mediated by viral protein hemagglutinin (HA), which recognizes cell surface glycoconjugates that terminate in $\alpha$-sialosides. To develop antiinfluenza drugs based on inhibition of HA-mediated infection, novel fluorescent nanoparticles displaying multiple biantennary $N$-glycan chains with $\alpha$-sialosides (A2-PC-QDs) that have high affinity for the HA were designed and constructed. The A2-PC-QDs enabled an easy and efficient fluorescence polarization (FP) assay for detection of interaction with the HA and competitive inhibition even by small molecule compounds against A2-PC-QDs-HA binding. The quantum dot (QD)-based FP assay established in the present study is a useful tool for high-throughput screening and to accelerate the development of novel and more effective blockers of the viral attachment of influenza virus. (120 words)
\end{abstract}

Highlights - Fluorescent nanoparticles displaying multiple $N$-glycan with $\alpha$-sialosides were constructed. - Fluorescence polarization was detected in interaction of the particle with the HA.

- Competitive inhibition with a derivative of sialic acid was observed between the $\alpha$-sialosides and the HA. - The FP assay is useful for screening of HA blockers.

Keywords; influenza virus, hemagglutinin, fluorescence polarization, quantum dot, high-throughput screening. 


\section{Introduction}

Influenza A viruses are responsible for seasonal outbreaks and infrequent pandemics. M2 ion channel inhibitors, amantadine and rimantadine, are active against influenza A virus, but their clinical use is limited by emergence of transmissible drug-resistant strains (Hayden and Hay, 1992). Neuraminidase inhibitors, oseltamivir, zanamivir, peramivir, and laninamivir, are licensed for the treatment and prevention of seasonal influenza (Babu et al., 2000; Gubareva, 2004; Yamashita et al., 2009). These drugs also possess potential to reduce virus transmission and mortality during the next pandemic. Hemagglutinin (HA) is also a potential target of antiviral drugs because of its key roles in the initial stages of infection. To address the need for new antiviral drugs against influenza, a number of studies have been made for inhibitors of receptor binding (Matrosovich et al., 1990; Mochalova et al., 1994) or membrane fusion (Luo et al., 1997; Yoshimoto et al., 1999).

Molecular interaction of protein with its receptor is most primitive and essential biological event indicating the presence of biological activity. Fluorescence polarization (FP) assay is one of the few methods that can detect molecular interactions without use of radioisotopes. Other methods include surface plasmon resonance (Schuck, 1997), calorimetry (Sigurskjold, 2000), frontal chromatography (Ng et al., 2005), and two-dimensional nuclear magnetic resonance (NMR) spectroscopy (Shuker et al., 1996). The FP assay is based on physical property of small molecules, which rotate more rapidly than large molecules in solution (Freyssinet et al., 1978; Perrin, 1926). When a small fluorescent molecule is excited with plane-polarized light, the emitted light is largely depolarized, showing low polarization value, $\mathrm{P}$, which is calculated as difference of the vertical and horizontal intensities. Large 
molecules caused by the binding of a second molecule, rotate little during the excited state, and therefore have high polarization values. The unique features of FP allowed for development of simple and homogeneous assays in the microplate format (Nikolovska-Coleska et al., 2004).

In the present study, quantum dots (QDs) having sialylated $N$-glycan chains as a new class fluorescent glycocluster nanoparticles were designed and prepared as a receptor of the HAs and their feasibility in FP-based high-throughput screening system of HA blockers was demonstrated.

\section{Materials and methods}

\subsection{Reagents and the preparation of $A 2-P C-Q D s$}

Qdot 545 ITK Organic Quantum Dots were purchased from Invitrogen (Calsbad, CA, USA). Egg yolk sialylated glycopeptide (A2 glycopeptide) was purchased from TCI (Tokyo, Japan). 11Mercaptoundecylphosphorylcholine (PC-SH) and 11,11'-dithio bis [undec-11-yl 12- (aminooxyacetyl) amino hexa (ethyleneglycol) ] (ao-SH) were synthesized by the procedures reported previously (Holmlin RE et al., 2001; Nagahori et al., 2009; Ohyanagi et al., 2011). The ao-PC-QDs were prepared from the above Qdot 545 ITK, trioctylphosphine oxide (TOPO)-coated QDs (100 $\mu \mathrm{L}$ of 1 $\mu \mathrm{M}$ solution, $\left.5.8 \mathrm{~nm}, \mathrm{CdSe} / \mathrm{ZnS}, \lambda_{\mathrm{em}}=545 \mathrm{~nm}\right)$, by a general protocol for coating with ao-SH $(50 \%)$ and PC-SH (50\%). Sialylated biantennary $N$-glycan (A2) prepared by treating A2 glycopeptide with PNGase F (Roche Diagnostics Japan, Tokyo, Japan) was subjected to coupling with ao-PC-QDs by the "glycoblotting" (Nishimura et al., 2005; Ohyanagi et al., 2011) reaction and gave PC-QDs displaying A2 glycans (A2-PC-QDs, Figure 1). Characterization of A2-PC-QDs was performed by 
direct MALDI-TOFMS (Nagahori et al., 2009; Ohyanagi et al., 2011) and the results showed the advent of an expected molecular ion signal at $\mathrm{m} / \mathrm{z} 3155.7$ corresponding to the heterodisulfide A2-SS-PC instead of disappearance of the signal at $\mathrm{m} / \mathrm{z} 908.7$ due to ao-S-S-PC corresponding to free aminooxy-functional groups. As standards or simple model compounds in the competitive binding assay, 2-aminobenzamide (2AB) labeled A2 (2AB-A2, 1) (Dell et al., 2008), and two known sialosides, methyl 5-acetamido-3,5-dideoxy-D-glycero- $\alpha$-D-galacto-2-nonulopyranosonic acid (2) (Sauter et al., 1992) and octyl 5-acetamido-3,5-dideoxy-D-glycero- $\alpha$-D-galacto-2-nonulopyranosonic acid (3) (Crich and Li, 2007), were also used.

\subsection{Viruses and cells}

Influenza virus A/Puerto Rico/8/1934 (H1N1) was propagated in allantoic cavities of 10-day-old embryonated chicken eggs at $35^{\circ} \mathrm{C}$ for 2 days and stored at $-80^{\circ} \mathrm{C}$ until use. The virus was also purified by differential centrifugation and sedimentation through a sucrose gradient (Kida and Yanagawa, 1979). Mardin-Darby canine kidney (MDCK) cells were grown in minimal essential medium (MEM, Nissui Pharmaceutical, Tokyo, Japan) supplemented with 10\% calf serum and used for antiviral assay.

\subsection{Hemagglutinin purification}

HA protein was prepared from purified virus by bromelain (Sigma-Aldrich, Tokyo, Japan) digestion, which was performed for $6 \mathrm{~h}$ at $37^{\circ} \mathrm{C}$ in Tris Buffer $(10 \mathrm{mM} \mathrm{pH} 8.0,25 \mathrm{mM} 2$ mercaptoethanol) at virus protein: bromelain 5:1. Digestion was terminated using a complete protease inhibitor cocktail (Roche Diagnostics Japan, Tokyo, Japan). Bromelain-treated HA (BroHA) was 
purified by sucrose gradient centrifugation ( $5-20 \%$ sucrose) and the fractions around $15 \%$ sucrose were collected. The BroHA was ultracentrifuged again and the pellet was diluted in phosphate buffered saline (PBS).

2.4 FP assay

A freshly prepared solution of A2-PC-QDs and BroHA in PBS with $0.05 \%$ Tween 20 was added to increase the amount of the mixture to a total $200 \mu \mathrm{L}$. FP measurements were performed on a multiplate reader POWERSCAN 4 (DS Pharma Biomedical, Osaka, Japan) equipped with polarizers using a dual path length quartz cell. The fluorophores were excited with vertical polarized light at $485 \mathrm{~nm}$ and the intensity of the emitted light was observed through vertical and horizontal polarizers at 546 nm. The correction factor $\mathrm{G}$ was determined by excitation with horizontal-polarized light and observation of the emitted light through vertical and horizontal polarizers.

\subsection{HI assay}

Before the hemagglutination-inhibition (HI) assay, compounds were incubated with $0.5 \%$ chicken red blood cells (RBCs) in PBS and it was confirmed whether they have hemagglutination (HA) activity. HI tests were performed according to the microtiter method of Sever (Sever, 1962). Briefly, $25 \mu \mathrm{L}$ of serial two-fold dilutions of the compounds were mixed with 4 HA units of the virus in Ubottom microtiter plates and incubated at room temperature for $30 \mathrm{~min}$. Then $50 \mu \mathrm{L}$ of $0.5 \%$ chicken RBCs was added to each well and incubated at room temperature for $30 \mathrm{~min}$. The HI titer was expressed as the reciprocal of the highest serum dilution that completely inhibited hemagglutination of 4 HA units of the virus. 


\subsection{In vitro antiviral assay}

Antiviral effect was assessed by plaque inhibition on MDCK cells using 25-100 plaque-forming units (pfu) of the virus. The compounds and virus were mixed and incubated at room temperature for 1 hour and added to plates pre-cultured with MDCK cells. After incubation at $35^{\circ} \mathrm{C}$ for $1 \mathrm{~h}$, the virus solution was thrown away and cells were washed with PBS, then agar medium was added and incubated at $35^{\circ} \mathrm{C}$ for $48 \mathrm{~h}$. The gel was stained with $0.005 \%$ neutral red and plaques were counted. The percentage of plaque inhibition was calculated as the reduction rate compared with the number of plaques without the compound.

\section{Results}

\subsection{Preparation of a new fluorescent probe for FP-based HA assay.}

According to the versatile synthetic method (Ohyanagi et al., 2011) by combined use of an aminooxy-terminated thiol derivative (ao-SH) and a PC derivative (PC-SH), a novel Glyco-PC-QDs having biantennary $N$-glycan chains (A2-PC-QDs) was prepared (Figure 1). Concentration of A2-PCQDs dissolved in the stock solution derived from the starting TOPO-coated QDs was determined, at which the fluorescent signal was sufficiently higher than the background of the buffer solution. As a result, the concentration of A2-PC-QDs was $10 \mathrm{nM}$ and the FP value was approximately $100 \mathrm{mP}$, which was high enough to obtain a reliable FP value.

\subsection{Binding of A2-PC-QDs to the HA of influenza virus}


Binding of A2-PC-QDs to the HA of A/Puerto Rico/1934 (H1N1) was measured by direct titration with BroHA, which is a soluble form of HA that lacks the $C$-terminal anchoring peptide (Gamblin et al., 2004). BroHA of various concentrations was added to $10 \mathrm{nM} \mathrm{A2-PC-QDs} \mathrm{and} \mathrm{incubated} \mathrm{at} \mathrm{room}$ temperature. FP values were recorded at $0 \mathrm{~min}, 30 \mathrm{~min}, 1 \mathrm{~h}, 2 \mathrm{~h}$, and $3 \mathrm{~h}$ after the addition of BroHA. As a result, $512,000 \mathrm{HA} / \mathrm{mL}$ BroHA was saturated for more than $2 \mathrm{~h}$ and the FP value was about 350 mP (Fig. 2). When PC-QDs coated only with PC-SH were added to the same concentration of BroHA instead of A2-PC-QDs, changes in the FP value were not observed. Furthermore, $1 \mathrm{mg} / \mathrm{mL}$ bovine serum albumin (BSA) instead of BroHA also did not influence the FP value of A2-PC-QDs (data not shown). These results demonstrate clearly that A2 glycan-specific recognition by BroHA is crucial for the binding detected by FP analysis.

\subsection{Binding assay by competitive fluorescence polarization}

The specific binding of A2-PC-QDs and BroHA was competitively inhibited by 2AB-A2 (1). The effective concentration of 2AB-A2 was more than $1 \mathrm{mM}$ and the binding of A2-PC-QDs with BroHA was completely inhibited with the addition of $4 \mathrm{mM} 2 \mathrm{AB}-\mathrm{A} 2$ (Fig. 3). To test the feasibility of this method for screening HA blockers as candidates for anti-influenza drugs, we employed preliminarily two known simple derivatives of sialic acid, methyl sialoside (2), which is already known to bind with the BroHA of X-31 strain (Sauter et al., 1992), and octyl sialoside (3). Each compound was added to a mixture of A2-PC-QDs and BroHA in the concentration range designated for the quantitative FP assay. During the titration of compound 2, no significant change in the FP value was observed, even at $20 \mathrm{mM}$. On the other hand, a dose-dependent inhibitory effect on the FP value was observed 
during the titration of more than $5 \mathrm{mM}$ of compound 3, suggesting the importance of the hydrophobic nature of the aglycon region of synthetic sialosides in the interaction with HA.

\subsection{Antiviral effects of the selected compounds.}

To assess the antiviral effects of the compounds used herein, the inhibitory effect of compound $\mathbf{3}$ on the viral infection against MDCK cells was examined. Compound $\mathbf{3}$ at a concentration of 19.2 $\mathrm{mM}$ showed a significant inhibitory effect as the number of plaques was reduced by approximately $72 \%$ inhibition compared to that without the compound, and compound 2 at concentration of 23.2 $\mathrm{mM}$ showed a similar antiviral effect, with approximately $63 \%$ inhibition of plaque formation. Unexpectedly, compound $\mathbf{3}$ as well as $\mathbf{2}$ exhibited no significant HI activity (data not shown). These observations clearly indicate that the FP-based HA binding assay using A2-PC-QDs is much more sensitive than the usual HI assay. In other words, it was suggested that the generally low affinity of HA with simple small sialosides could also be detected by amplified sensitivity during the interaction with a mono-dispersed spherical nanoparticular fluorescent probe having multiple sialyl $N$-glycans that mimic cell-surface glycoproteins.

\section{Discussion}

In the present study, an easy screening method with high potential for searching for HA blockers was established on the basis of FP assay. It deserves to be noted that Weinhold et al. (Weinhold and Knowles, 1992) first reported the characteristic features of the binding between $\alpha$-sialosides and the HA of influenza virus using the FP assay. However, it is considered that the affinity between 
common simple and monovalent-type sialosides and HA appeared to be very low and this must be an obstacle for further application of the FP-based assay to practical screening systems.

To assess a broad range of compounds targeting HA blockers by a simple and versatile assay system, a novel class of fluorescent nanoparticles displaying multiple sialyl $N$-glycans, A2-PC-QDs, was designed and prepared. It is well known that a variety of multivalent-type receptors bearing sialic acids show highly enhanced affinity to HAs (Feng et al., 2010; Ogata et al., 2009; Ohta et al., 2003). To amplify the low affinity between simple oligosaccharides and HA, glycan-modified high performance quantum dots (Glyco-PC-QDs) (Ohyanagi et al., 2011) that can be used for live animal imaging by near-infrared fluorescence photometry due to the non-fouling nature of QDs coated by phosphorylcholine self-assembled monolayers were employed. Although colorful Glyco-PC-QDs have proved to become highly sensitive fluorescent probes for direct imaging of living cells and animals by employing common fluorescence microscopic devices (Ohyanagi et al., 2011), no examples have indicated the feasibility of these ligand-conjugated QDs in quantitative analysis aiming for high-throughput screening toward drug discovery research. Thus, the potential of A2-PC-QDs in FP-based quantitative analysis of targeted molecular interactions was examined since the non-fouling surface of A2-PC-QDs appeared to be very beneficial to avoid unfavorable non-specific protein adsorption (Ohyanagi et al., 2011).

It is known that the polarization value $\mathrm{P}$ used in the fluorescence polarization assay obeys the definition:

$$
P=\left(I_{\text {parallel }}-I_{\text {perpendicular }}\right) /\left(I_{\text {parallel }}+I_{\text {perpendicular }}\right)
$$


where $I_{\text {parallel }}$ is the fluorescence component parallel to the linearly polarized light used for excitation and $I_{\text {perpendicular }}$ is the fluorescence component normal to that (Perrin, 1926). In the present study, FP value of A2-PC-QDs was approximately $100 \mathrm{mP}$, which was high enough to obtain a reliable FP value. After reaction between A2-PC-QDs and BroHA, the FP value became high, indicating that large molecules caused by the binding rotated slowly during the excited state in the solution. As anticipated, A2-PC-QDs were highly sensitive fluorescent ligands suitable for an easy FP-based quantitative assay for screening small molecular HA blockers by simple competitive assay using standard compounds 1-3. It should also be noted that the strength of the affinity of A2-PC-QDs with HA can be controlled by varying the ratio of ao-SH and PC-SH in ao-PC-QDs, a key intermediate to display any glycoforms (Ohyanagi et al., 2011). It is clear that the present method is a useful tool for the first screening to profile large numbers of small molecules as potential blockers in the viral attachment step of influenza viruses.

\section{Acknowledgements}

The authors wish to thank Dr. M. Yamashita and H. Hayasaka, Daiichi Sankyo Co., Ltd., Tokyo, Japan, for their valuable advice. The authors also wish to thank Mr. K. Taniuchi, DS Pharma Biomedical Co., Ltd., Osaka, Japan for his technical support. This work was funded by Daiichi Sankyo Co., Ltd., Tokyo 134-8630, Japan, and partly supported by a program, "Innovation COE program for future drug discovery and medical care" from the Ministry of Education, Culture, Science, and Technology, Japan. 


\section{References}

Babu, Y.S., Chand, P., Bantia, S., Kotian, P., Dehghani, A., El-Kattan, Y., Lin, T.H., Hutchison, T.L., Elliott, A.J., Parker, C.D., Ananth, S.L., Horn, L.L., Laver, G.W. Montgomery, J.A., 2000. BCX-1812 (RWJ-270201): discovery of a novel, highly potent, orally active, and selective influenza neuraminidase inhibitor through structure-based drug design. J. Med. Chem. 43, 3482-3486.

Crich, D. Li, W., 2007. O-sialylation with N-acetyl-5-n,4-o-carbonyl-protected thiosialoside donors in dichloromethane: facile and selective cleavage of the oxazolidinone ring. J. Org. Chem. 72, 2387-2391.

Dell, A., Lee, J.J., Pang, P.C., Parry, S., Smith, M.S., Tissort, B., Morris, H.R., Panico, M. Haslam, S.M. 2008. Glycomics and mass spectrometry. In: Fraser-Reid, B.O., Tatsuta, K. and Thiem, J. (Eds), Glycoscience, Chemistry and Chemical Biology, Springer-Verlag Berlin Heidelberg, Berlin, Heidelberg, pp. 2191-2217.

Feng, F., Miura, N., Isoda, N., Sakoda, Y., Okamatsu, M., Kida, H. Nishimura, S.I., 2010. Novel trivalent anti-influenza reagent. Bioorg. Med. Chem. Lett. 20, 3772-3776.

Freyssinet, J.M., Lewis, B.A., Holbrook, J.J. Shore, J.D., 1978. Protein-protein interactions in blood clotting. The use of polarization of fluorescence to measure the dissociation of plasma factor XIIIa. Biochem. J. 169, 403-410.

Gamblin, S.J., Haire, L.F., Russell, R.J., Stevens, D.J., Xiao, B., Ha, Y., Vasisht, N., Steinhauer, D.A., Daniels, R.S., Elliot, A., Wiley, D.C. Skehel, J.J., 2004. The structure and receptor binding properties of the 1918 influenza hemagglutinin. Science 303, 1838-1842.

Gubareva, L.V., 2004. Molecular mechanisms of influenza virus resistance to neuraminidase inhibitors. Virus Res. 103, 199-203.

Hayden, F.G. Hay, A.J., 1992. Emergence and transmission of influenza A viruses resistant to amantadine and rimantadine. Curr. Top. Microbiol. Immunol. 176, 119-130.

Holmlin RE, Chen X, Chapman RG, Takayama S GM., W., 2001. Zwitterionic SAMs that Resist Nonspecific Adsorption of Protein from Aqueous Buffer. Langmuir 17, 2841-2850.

Kida, H. Yanagawa, R., 1979. Isolation and characterization of influenza a viruses from wild freeflying ducks in Hokkaido, Japan. Zentralbl Bakteriol Orig A 244, 135-143.

Luo, G., Torri, A., Harte, W.E., Danetz, S., Cianci, C., Tiley, L., Day, S., Mullaney, D., Yu, K.L., Ouellet, C., Dextraze, P., Meanwell, N., Colonno, R. Krystal, M., 1997. Molecular mechanism underlying the action of a novel fusion inhibitor of influenza A virus. J. Virol. 71, 4062-4070. 
Matrosovich, M.N., Mochalova, L.V., Marinina, V.P., Byramova, N.E. Bovin, N.V., 1990. Synthetic polymeric sialoside inhibitors of influenza virus receptor-binding activity. FEBS Lett. 272, 209-212.

Mochalova, L.V., Tuzikov, A.B., Marinina, V.P., Gambaryan, A.S., Byramova, N.E., Bovin, N.V. Matrosovich, M.N., 1994. Synthetic polymeric inhibitors of influenza virus receptor-binding activity suppress virus replication. Antiviral Res. 23, 179-190.

Nagahori, N., Abe, M. Nishimura, S.I., 2009. Structural and functional glycosphingolipidomics by glycoblotting with an aminooxy-functionalized gold nanoparticle. Biochemistry. 48, 583-594.

Ng, E.S., Yang, F., Kameyama, A., Palcic, M.M., Hindsgaul, O. Schriemer, D.C., 2005. Highthroughput screening for enzyme inhibitors using frontal affinity chromatography with liquid chromatography and mass spectrometry. Anal. Chem. 77, 6125-6133.

Nikolovska-Coleska, Z., Wang, R., Fang, X., Pan, H., Tomita, Y., Li, P., Roller, P.P., Krajewski, K., Saito, N.G., Stuckey, J.A. Wang, S., 2004. Development and optimization of a binding assay for the XIAP BIR3 domain using fluorescence polarization. Anal. Biochem. 332, 261-273.

Nishimura, S.I., Niikura, K., Kurogochi, M., Matsushita, T., Fumoto, M., Hinou, H., Kamitani, R., Nakagawa, H., Deguchi, K., Miura, N., Monde, K. Kondo, H., 2005. High-throughput protein glycomics: Combined use of chemoselective glycoblotting and MALDI-TOF/TOF mass spectrometry. Angewandte Chemie-International Edition 44, 91-96.

Ogata, M., Hidari, K.I., Kozaki, W., Murata, T., Hiratake, J., Park, E.Y., Suzuki, T. Usui, T., 2009. Molecular design of spacer-N-linked sialoglycopolypeptide as polymeric inhibitors against influenza virus infection. Biomacromolecules 10, 1894-1903.

Ohta, T., Miura, N., Fujitani, N., Nakajima, F., Niikura, K., Sadamoto, R., Guo, C.T., Suzuki, T., Suzuki, Y., Monde, K. Nishimura, S.I., 2003. Glycotentacles: synthesis of cyclic glycopeptides, toward a tailored blocker of influenza virus hemagglutinin. Angew. Chem. Int. Ed. Engl. 42, 5186-5189.

Ohyanagi, T., Nagahori, N., Shimawaki, K., Hinou, H., Yamashita, T., Sasaki, A., Jin, T., Iwanaga, T., Kinjo, M. Nishimura, S.I., 2011. Importance of sialic acid residues illuminated by live animal imaging using phosphorylcholine self-assembled monolayer-coated quantum dots. J. Am. Chem. Soc. 133, 12507-12517.

Perrin, F., 1926. Polarisation de la lumière de fluorescence. Vie moyenne des molécules dans l'etat excité. J. Phys. Radium 7, 390-401.

Sauter, N.K., Hanson, J.E., Glick, G.D., Brown, J.H., Crowther, R.L., Park, S., Skehel, J.J. Wiley, D.C., 1992. Binding of influenza virus hemagglutinin to analogs of its cell-surface receptor, sialic acid: analysis by proton nuclear magnetic resonance spectroscopy and X-ray crystallography. Biochemistry (Mosc). 31, 9609-9621. 
Schuck, P., 1997. Use of surface plasmon resonance to probe the equilibrium and dynamic aspects of interactions between biological macromolecules. Annu. Rev. Biophys. Biomol. Struct. 26, 541-566.

Sever, J.L., 1962. Application of a microtechnique to viral serological investigations. J. Immunol. 88, 320-329.

Shuker, S.B., Hajduk, P.J., Meadows, R.P. Fesik, S.W., 1996. Discovering high-affinity ligands for proteins: SAR by NMR. Science 274, 1531-1534.

Sigurskjold, B.W., 2000. Exact analysis of competition ligand binding by displacement isothermal titration calorimetry. Anal. Biochem. 277, 260-266.

Weinhold, E.G. Knowles, J.R., 1992. Design and evaluation of a tightly binding fluorescent ligand for influenza A hemagglutinin. J. Am. Chem. Soc. 114, 9270-9275.

Yamashita, M., Tomozawa, T., Kakuta, M., Tokumitsu, A., Nasu, H. Kubo, S., 2009. CS-8958, a prodrug of the new neuraminidase inhibitor R-125489, shows long-acting anti-influenza virus activity. Antimicrob. Agents Chemother. 53, 186-192.

Yoshimoto, J., Kakui, M., Iwasaki, H., Fujiwara, T., Sugimoto, H. Hattori, N., 1999. Identification of a novel HA conformational change inhibitor of human influenza virus. Arch. Virol. 144, 865878. 


\section{Figure legends}

Figure 1. Chemical structures of A2-PC-QDs and compounds (1-3) used in this study.

Figure 2. Fluorescence polarization (FP)-based monitoring of the interaction between A2-PC-QDs and BroHA. A2-PC-QDs at $10 \mathrm{nM}$ and serial two-fold-diluted BroHA derived from A/Puerto Rico/8/1934 (H1N1) were added to PBS with 0.05\% Tween 20. The FP value was measured and calculated at various incubation times after mixing the solution.

Figure 3. Competitive inhibition by $2 \mathrm{AB}-\mathrm{A} 2$ to binding of $\mathrm{A} 2-\mathrm{PC}-\mathrm{QD}$ s with BroHA using fluorescence polarization (FP) assay. A2-PC-QDs at $10 \mathrm{nM}$ and BroHA at 512,000HA/ml were mixed with various concentrations of 2AB-A2 (1). After incubation for $2 \mathrm{~h}$ at room temperature, the FP value was measured and calculated.

Figure 4. Competitive inhibition by 2 (A) and 3 (B) of interaction of A2-PC-QDs and BroHA assessed by the FP assay. A2-PC-QDs at $10 \mathrm{nM}$ and BroHA at 512,000HA/ml were mixed with various concentrations of compound $\mathbf{1}$ or $\mathbf{2}$. After incubation for $2 \mathrm{~h}$ at room temperature, the FP value was measured and calculated. 
Fig. 1 Okamatsu et al.

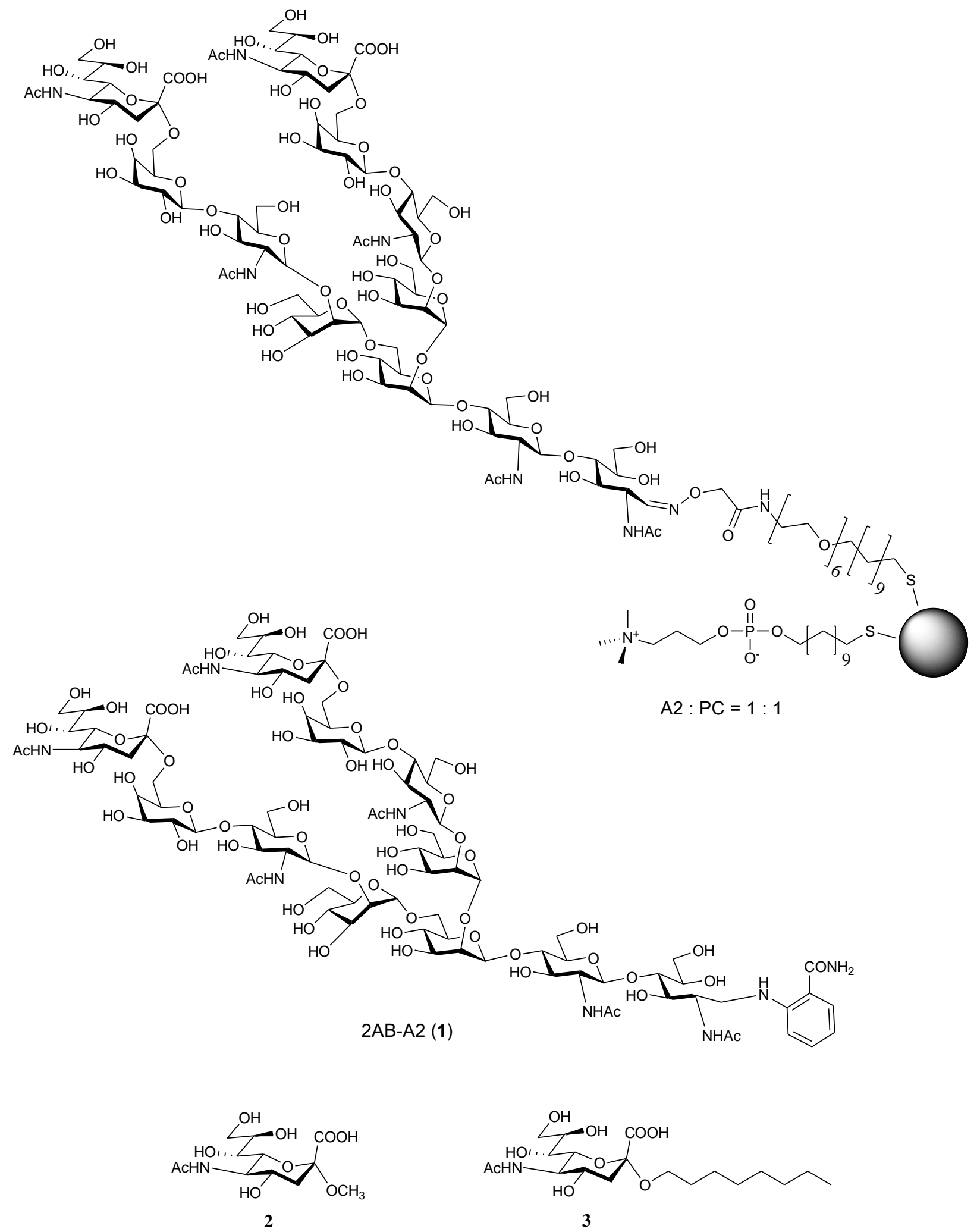


Fig. 2 Okamatsu et al.

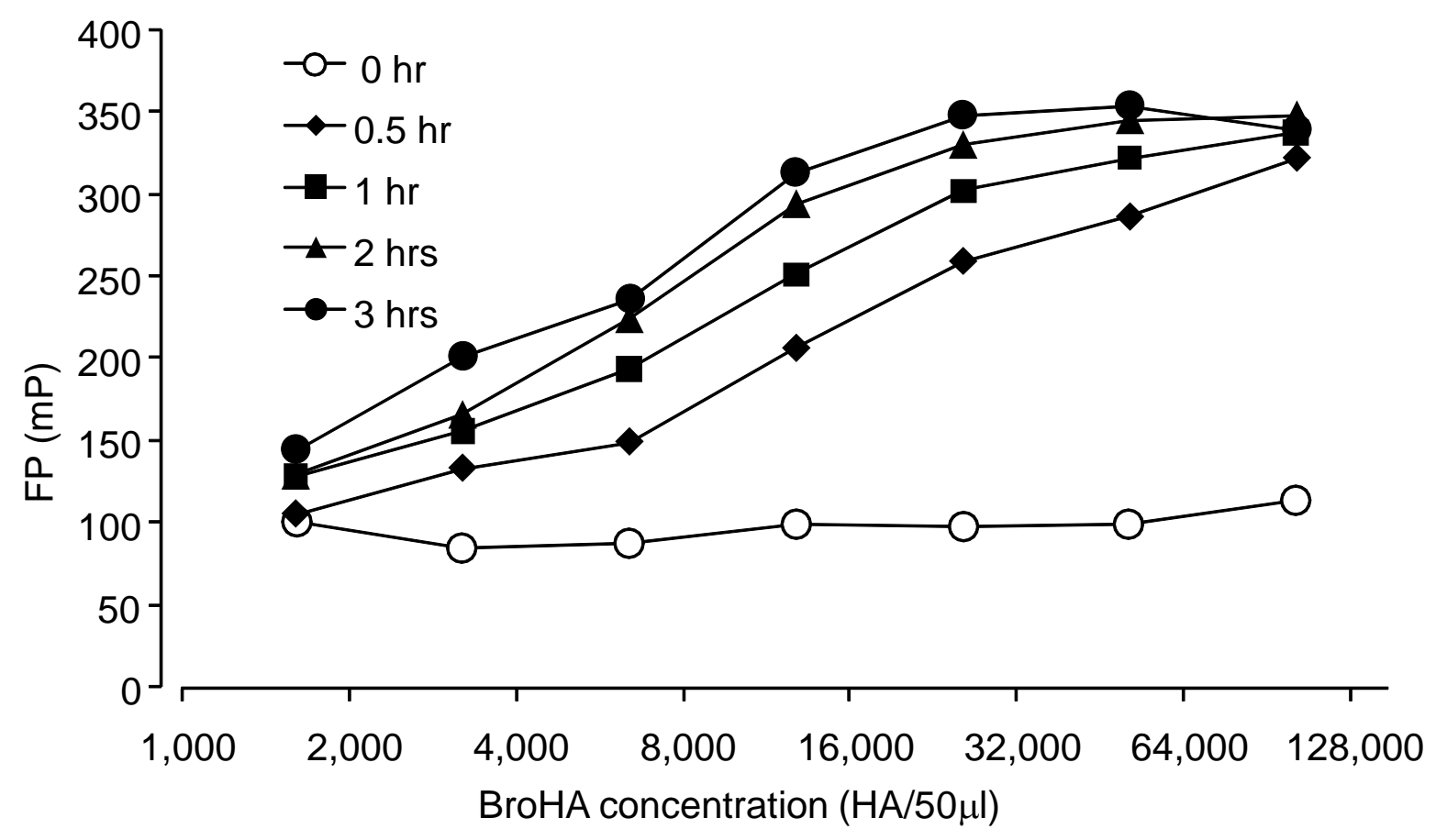


Fig. 3 Okamatsu et al.

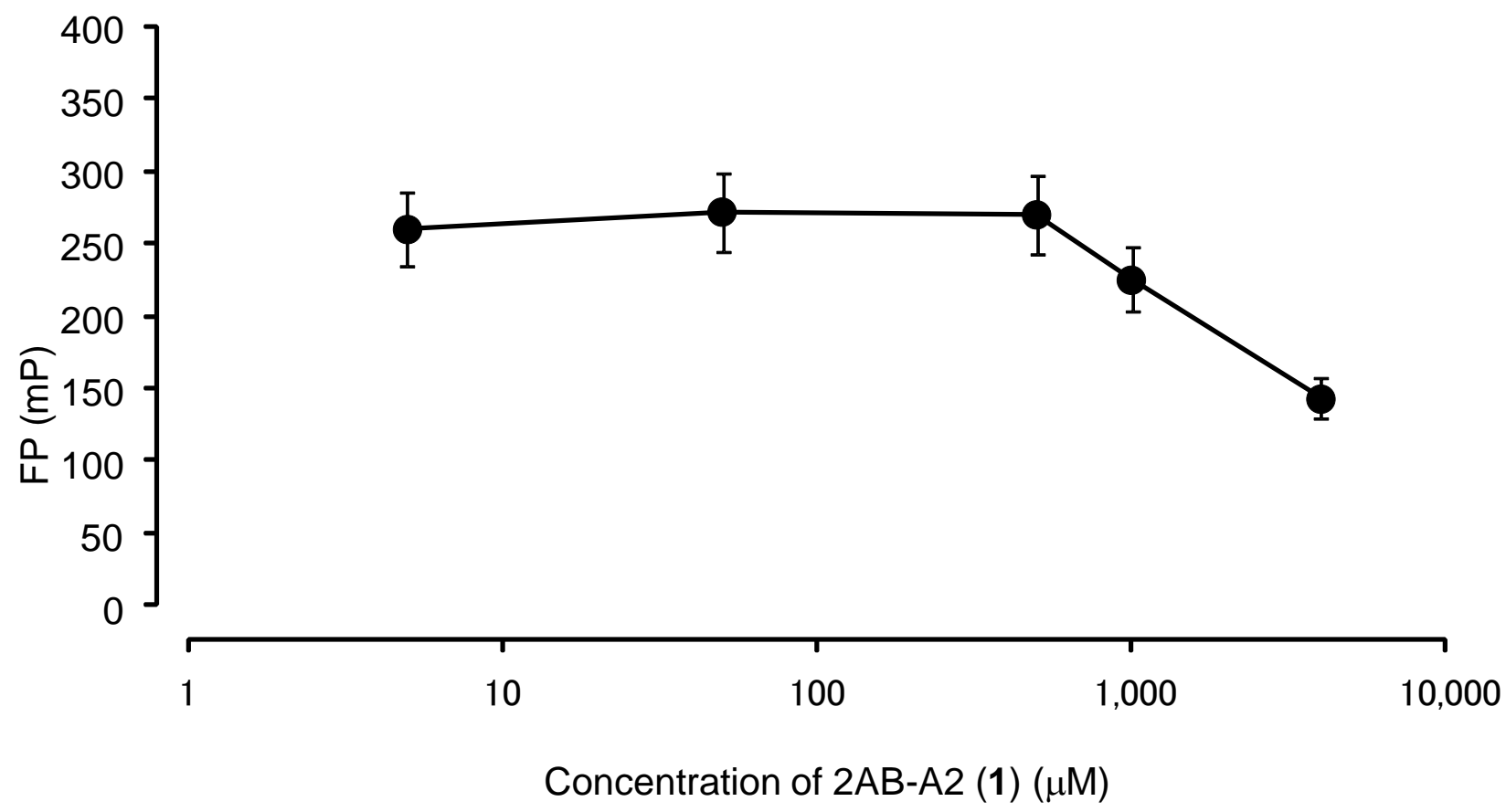


Fig. 4 Okamatsu et al.

A.
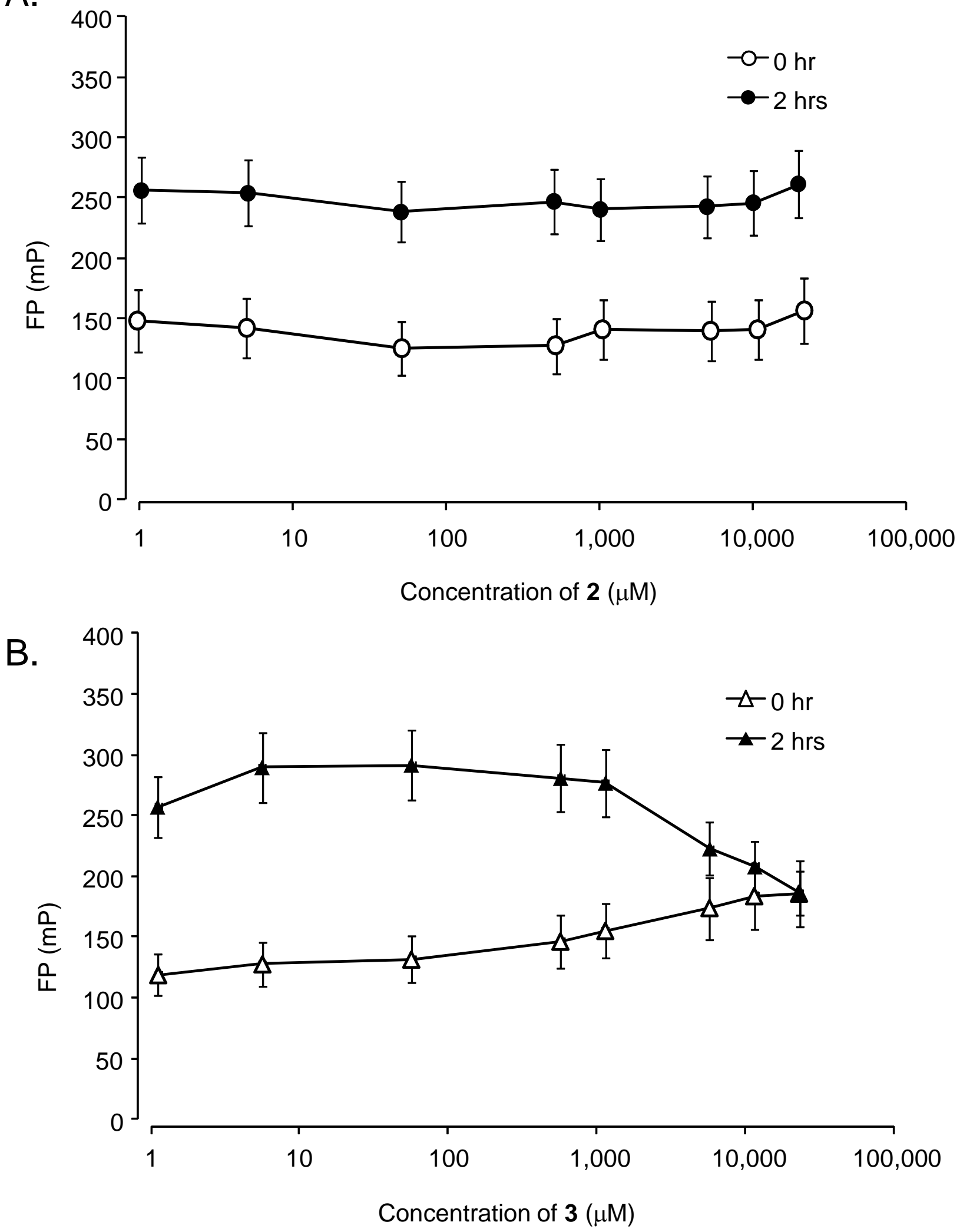